\title{
EL LENGUAJE Y SU APRENDIZAJE SEGÚN QUINE
}

\author{
Juan José DIEEZ RUIZ \\ Tutor de Filosofia. UNED Marbella
}

El lenguaje como conjunto de disposiciones

Se comprenderá mejor la epistemología de Quine si examinamos la psicología en la que se fundamenta, a saber, la psicología conductista. Sus tesis clásicas de la indeterminación de la traducción, la inescrutabilidad de la referencia o la relatividad ontológica se establecen explícitamente «desde el punto de vista de la conducta». El lugar privilegiado donde florece esta perspectiva es en el aprendizaje primitivo del lenguaje. A examinar su concepto de lenguaje y las formas de aprendizaje que propone dedicaremos este trabajo.

Quine cree, de manera general, que el lenguaje es una respuesta muscular que se aprende, en los primeros niveles, por condicionamiento. En concreto, lo define como "un conjunto socialmente inculcado de disposiciones" 1 , o como "el complejo de las disposiciones presentes respecto del comportamiento verbal» ${ }^{2}$. Aquí la cuestión es saber qué es una disposición. Quine la define como «una propiedad presente en el objeto por virtud de la cual las circunstancias $c$ causan que el objeto haga as 3 . La sal, por ejemplo, es una substancia que tiene la disposición de la solubilidad en agua, lo cual quiere decir que las circunstancias $c$ (estar en el agua) determinan que la sal haga a (se disuelva). Una disposición, en pocas palabras, es lo que una cosa está determinada a hacer en unas circunstancias específicas. El niño tiene la disposición a la conducta verbal porque,

1 W. V. QUINe, Palabra y objeto, Barcelona, 1968, p. 58.

2 W. V. QUINE, op. cit., p. 58

3 W. V. QUINE, Las ratces de la referencia, Madrid, 1977, p. 22 
por ejemplo, en las circunstancias de ver algo que es rojo, está dispuesto a emitir la respuesta verbal «rojo». Al bebé le inculca la sociedad un conjunto de disposiciones semejantes a la de "rojo", un conjunto de respuestas verbales que ha de producir en determinadas circunstancias estimulativas, y eso es el lenguaje. Así pues, las palabras y las oraciones no son más que respuestas musculares laríngeas emitidas ante estímulos seleccionados por la sociedad (representada por los padres o instructores). La asociación entre palabras y circunstancias es llevada a cabo gracias al refuerzo. Así, el bebé comienza a hablar porque ha sido condicionado a emitir determinadas palabras ante determinados estímulos, lo cual significa que la conducta verbal está controlada en su origen por variables externas, del ambiente, y no por variables internas, «mentales». He aquí el primer gran dogma del aprendizaje conductista del lenguaje que asume nuestro autor.

Sin embargo, Quine cree que no debemos contentarnos con las disposiciones, debemos aspirar a descubrir la infraestructura física que las hace posibles, "el hipotético estado o mecanismo que todavía no entendemos...» ${ }^{4}$. $\mathrm{O}$ sea, no debemos contentarnos con la solubilidad, hay que llegar al mecanismo molecular que la hace posible. No debemos contentarnos con observar la conexión entre las palabras y sus circunstancias de emisión, debemos aspirar a descubrir qué mecanismos neuronales explican esa asociación. En el caso de la sal, la ciencia ha dado con la microestructura física que explica la solubilidad, en el caso de la disposición a decir «rojo» ante las circunstancias rojas, todavía no. En el fondo, éste es, ni más ni menos, el fisicalismo al que aspiraba Carnap y el Círculo de Viena: la reducción, en este caso de la psicología, al lenguaje de la física, a partículas y sus movimientos. La cuestión es que, como la explicación fisicalista de la mente está muy lejana, Quine piensa que el único modo de aproximarnos al lenguaje es el disposicional conductista.

¿Es la explicación disposicional conductista del lenguaje una verdadera explicación? Mi opinión es que tiene todo el aspecto de ser una explicación meramente verbal, pues tratamos de definir el lenguaje (algo desconocido) mediante las disposiciones (algo desconocido, en su estructura microfisica), ignotum per ignotius. Esto es algo parecido a la definición del sueño por una "virtus dormitiva». ¿Qué es el lenguaje?: la propiedad de estar dispuesto a emitir palabras en determinadas circunstancias, o sea, la propiedad de usar el lenguaje. El len-

4 W. V. QUINE, Las ratces de la referencia, p. 25. 
guaje es la posesión de una "virtus lingüística», pues, según Quine, es un conjunto de disposiciones ("virtus") a la conducta verbal ("lingüística»). Los hombres tienen una propiedad (desconocida en su mecanismo físico) por virtud de la cual las circunstancias $c$ causan una respuesta a base de determinados ruidos producidos por la musculatura laríngea. $\mathrm{O}$ sea, nos quedamos sin saber qué es el lenguaje.

Este carácter de explicación aparente pudiera tener sentido, sin embargo, si lo consideramos como una definición polémica que mira de reojo al mentalismo. Decir que el lenguaje es un conjunto de disposiciones es decir que no es un conjunto de otra cosa, en especial, que no es un sistema de significados y de reglas sintácticas representado en la mente del hablante, como lo definiría Chomsky. En realidad, creemos que en Quine la definición disposicional tiene el sentido de una definición negativa: aunque decir que el lenguaje es disposición a la conducta verbal es decir poca cosa, al menos excluye pensar que pueda ser un sistema de significados y reglas mentales.

Después de cuestionar la noción quineana de lenguaje por el lado de la poca capacidad explicativa de su definición en términos disposicionales, debemos atender a otro aspecto no menos importante de esa definición: las disposiciones en que consiste el lenguaje son «inculcadas socialmente» o, lo que es lo mismo, enseñadas por los padres. Los padres asocian las circunstancias presentes con las palabras en cuestión mediante refuerzo: así aprende el niño la disposición a decir "rojo" en presencia de estimulaciones rojas. ¿Cuál es, sin embargo, el mecanismo físico interno que permite esas asociaciones? Sólo somos capaces de apreciar la correlación externa entre sonidos, circunstancias y refuerzos, quedándonos así en un nivel superficial de explicación. Lo verdaderamente interesante, la microestructura física, la desconocemos. Sólo sabemos que debe ser innata. Esa estructura es una condición esencial, algo que pertenece desde siempre al objeto o a la substancia. Pues bien, lo que tenemos que investigar es qué estructura innata debemos postular para explicar justamente el que los padres puedan «inculcar disposiciones». Parece razonable suponer que es la estructura interna de su sistema cognitivo la que hace al hombre emitir respuestas verbales. Si esto es así, el tema fundamental de una psicología del lenguaje es describir ese sistema cognitivo. Y en fin, si las disposiciones, en el fondo, lo que hacen es remitirnos a un hipotético estado o mecanismo físico que todavía no entendemos, mejor sería tratar de hacer hipótesis sobre los mecanismos (como hacen Chomsky y los psicólogos cognitivos) que contentarse con la definición disposicional. 
Chomsky, por su parte, critica la noción del lenguaje como complejo de disposiciones a la conducta verbal basándose en que:

Presumiblemente un complejo de disposiciones es una estructura que puede ser representada como un conjunto de probabilidades de emisiones en ciertas "circunstancias" o "situaciones" definibles. Pero debe reconocerse que la noción de "probabilidad de una oración" es enteramente inútil, bajo cualquier interpretación conocida de ese término. Sobre bases empíricas, la probabilidad de que yo produzca una determinada oración en inglés - digamos, "los pájaros vuelan" o "el martes sigue al lunes", o cualquier otra- es indistinguible de la probabilidad de que produzca una oración determinada en japonés 5 .

En estricto espíritu skinneriano, las conductas verbales son operantes, respuestas, que se definen por su probabilidad de emisión. Lo que hace el refuerzo es determinar una probabilidad cada vez más alta de respuesta, a medida que avanza el aprendizaje, hasta llegar a una probabilidad prácticamente total cuando el aprendizaje culmina. En la conducta verbal, como en todo comportamiento operante, los refuerzos conectan (o hacen contingente) la respuesta verbal con ciertos estímulos seleccionados del exterior, de manera que la aparición de éstos en el futuro determina con probabilidad total la aparición de la respuesta verbal. Así pues, un conjunto de disposiciones debe entenderse como un conjunto de probabilidades de emisión en ciertas situaciones estimulativas definibles: ante estímulos rojos, un niño está dispuesto a emitir la palabra «rojo». Pero ocurre que, así como la probabilidad de que la sal se disuelva en agua es total, la probabilidad de que alguien en presencia de conejos diga "conejo" es, según Chomsky, prácticamente la misma de que hable en japonés. Quizás la probabilidad aumentaría si el protagonista de la escena en curso fuera un conejo, pero tampoco podríamos hablar de una probabilidad muy alta. Los conejos no sólo deben estar presentes, sino ser importantes en la ocasión; pero, ni aun así tendríamos algo más que una moderada probabilidad de emisión. Obviamente, si se declara un incendio, es predecible que el que primero lo vea grite: «Fuego!», pero también puede gritar «iAgua!», «Socorro!», «iBomberos!»; o llamar a su vecino, o mil cosas más, por muy probables que parezcan las anterio-

5 N. Chомsкx, "Quine's empirical assumptions", en D. Davidson y J. HintrkкA (eds.), Words and objections, Dordrecht, 1969, en p. 57. 
res. Ahora bien, si el control de las emisiones verbales por los estímulos se limita sólo a esos casos especiales, poca cosa explicamos, pues el lenguaje es algo más que gritos o interjecciones. Lo único que podría decir Quine es que una parte rutinaria, rígida y pequeña del lenguaje puede explicarse disposicionalmente. Pero para él esa no es la parte que se explica, sino otra muy importante: el lenguaje ostensivo y, en especial, las oraciones llamadas «observacionales" y sus significados estimulativos.

Quine en su réplica a Chomsky se defiende diciendo que : "Yo soy libre de seleccionar, de entre la totalidad de las disposiciones, cualesquiera que sean más favorables a mi propósito de identificar significados ostensivos" 6 . Nadie le discute su libertad, lo que se discute es si el lenguaje consiste en los significados ostensivos que él propone, los cuales pagan la ventaja de estar conectados con las circunstancias estimulativas al alto precio de quedar reducidos a gritos e interjecciones. Si de lo que se trata es de identificar "sus" significados ostensivos, al final lo que tendríamos sería un vocabulario inconexo. Pero jes eso un lenguaje? ¿Habría gramática, oraciones? Quine no se da por vencido ante la crítica de Chomsky:

La solubilidad en el agua sería una disposición bastante vacía si se definiese en términos de la probabilidad absoluta de disolución sin referencia a la circunstancia de estar en el agua (...). Las disposiciones verbales serían bastante vacías si se las definiese en términos de la probabilidad absoluta de emisión más allá del cielo. Yo, entre otros, he hablado fundamentalmente de disposiciones verbales en una circunstancia muy especifica: la circunstancia de un cuestionario, la de que se nos ofrezca una oración con la que asentir o disentir, o mostrarse indeciso o reaccionar extrañamente 7 .

Las disposiciones verbales han de concebirse en términos de la probabilidad de emisión relativa a la circunstancia de preguntar una oración. El niño no emitirá «rojo» en la mera presencia de rojo, sino si además se le pregunta «¿Rojo?». Quine quiere escabullirse recurriendo al contexto de pregunta/asen - timiento. La dificultad que, según él, señala Chomsky, es la de "establecer las condi-

6 W. V. Quine, "Reply to Chomsky", en D. Davidson y J. HintikKa (eds.), Words and objections, p. 308.

7 W. V. QUINE, "Reflexiones metodológicas sobre la teoría lingüística actual», Teorema, 6, 1972 , p. 122. 
ciones que disparan las disposiciones verbales». Quine habla de dos supuestos en los que se pueden determinar, mediante pregunta y asentimiento, las circunstancias estimulativas que disparan las respuestas. El primer caso es el de su famoso experimento mental de la traducción radical o sea, cuando un lingüista se enfrenta a la tarea de traducir el lenguaje de un indigena sin más recursos que anotar sus expresiones verbales ante circunstancias presentes. La traducción se hace sin manuales previos, sin intérpretes posibles, entre dos lenguas pertenecientes a culturas que no tienen tradición traductiva alguna en común. Imaginemos a Colón intentando traducir a los nativos de Guanahaní. El otro caso es el de un niño preguntando a su padre en los inicios de su aprendizaje del lenguaje. Ambos casos son ocasiones en las que, mediante el método de la pregunta se hace posible "horadar el barril de las disposiciones" 8 , o sea, averiguar qué circunstancias han de producir la emisión de qué palabras. Si un lingüista de campo pregunta "¿Gavagai?» en presencia de conejos y el indígena responde con su equivalente a "sím, entonces el investigador ha descubierto que son las condiciones leporinas las que disparan la respuesta del nativo. Si un niño pregunta a su padre en presencia de rojo la palabra "¿rojo?», y el padre responde "sím, el niño ha descubierto qué estímulos controlan la emisión de la respuesta verbal "rojo», ha descubierto la disposición del padre a decir "rojo» en presencia de rojo. Si la probabilidad, pues, no es absoluta, sino relativa a las circunstancias de preguntar en la ocasión, sí tiene sentido, según Quine, hablar de la probabilidad de emisión de una oración. El padre no dice "rojo", en circunstancias cualesquiera, sino cuando se le pregunta en presencia de rojo. Las disposiciones del adulto estarían ocultas a los ojos del niño si no existiera la capacidad de preguntar. En ese caso tendría razón Chomsky y ante una determinada situación estimulativa no se podría predecir qué respuesta verbal habría de ser emitida.

Sin embargo, el hecho de que el contexto pregunta/asentimiento sea ahora el lugar único donde es posible descubrir las disposiciones no creemos que resuelva el problema. Ya Chomsky, en la crítica citada más arriba, advierte que:

... la introducción de la noción de "probabilidad relativa a una situación" no cambia nada, al menos si las "situaciones" se caracterizan con cualquier fundamento objetivo conocido. Podemos, desde luego, elevar la probabilidad condicional de cualquier oración tan alta como queramos, incluso hasta la

8 W. V. QUINE, Ratces de la referencia, p. 63. 
unidad, respecto a situaciones especificadas, en condiciones especificadas, ad hoc. (...) pero de esta forma sólo unos pocos saludos convencionales, "clichés", y cosas por el estilo, tendrían la oportunidad de ser asociados al complejo de disposiciones que define el lenguaje 9 .

Podemos elevar la probabilidad de emisión restringiendo las condiciones de disparo, pero lo más que conseguiremos será descubrir las disposiciones en situaciones artificiales (como la pregunta corroborativa imaginada por Quine). En todo caso, lo que conseguiríamos así, insistimos, sería un lenguaje reducido a un vocabulario inarticulado, agramatical y no muy extenso. Hasta aquí la crítica de Chomsky.

Concedamos a Quine que las preguntas sirven para descubrir las disposiciones y que eso ocurre justamente en los casos de la traducción radical y del niño tratando de averiguar las disposiciones paternas. Sin embargo, también así existiría gran dificultad en aplicar la solución quineana, pues, en ambos supuestos, o los dos participantes en la comunicación desconocen la forma de preguntar/asentir del otro (como ocurre con el lingüista y el nativo), o uno de ellos la conoce muy imperfectamente, si es que la conoce (como ocurre con el niño).

En el caso del lingüista de la traducción radical, sería muy difícil que conociera el sistema indígena de preguntar, porque, por ejemplo, no todas las sociedades tienen marcadas las preguntas con una entonación ascendente. Algunas las pueden tener lexicalizadas por medio de sufijos. ¿Cómo podría entonces descubrirse en un lenguaje desconocido la semántica de un sufijo si ni siquiera conocemos la de los lexemas? En el caso del niño, la dificultad es de igual trascendencia. Quine parece ignorar que el preguntar y responder son habilidades relativamente tardías, que el nińo adquiere en torno a los tres años ${ }^{10} \mathrm{y}$, entonces, de manera tosca. Sin embargo, antes de esa edad, el bebé ya tiene un copioso vocabulario y una sintaxis de oraciones de más de tres palabras. ¿̨ómo ha aprendido ese vocabulario? ¿Cómo ha aprendido esas respuestas verbales si no dispone todavía del único método (el de pregunta/asentimiento) que le permite averiguar las disposiciones paternas? La posesión de vocabulario previa al

9 N. Сномsку, loc. cit., p. 57.

10 U. BELLUGI, "The development of interrogative structures in children's speech", en $\mathrm{K}$. RIEGEl (ed.), The development of language functions, Universidad de Michigan, 1965, pp. 103108. 
dominio del preguntar implica que el niño debe aprender sus primeras palabras sin el único método que admite Quine para que tenga sentido hablar de probabilidad relativa de emisión: el de pregunta/asentimiento. Por otra parte, la pregunta exige dominar el juego lingüístico del diálogo, y éste, el intercambio de papeles, las implicaciones conversacionales,...; en suma, conocer un «acto de habla».

La última línea de defensa de Quine ${ }^{11}$ es creer que el lingüista y el niño pueden descubrir las fórmulas de la pregunta/asentimiento con sólo observar que las circunstancias en las que el indígena y el padre dirían "sí", son las mismas que aquellas en las que estarían dispuestos a emitir la palabra. El padre dirá "sín a la pregunta "¿̨rojo?", en las mismas situaciones en que emitiría "rojo". El niño debe darse cuenta de que las condiciones del asentimiento son las mismas que las condiciones de la emisión. Pero el niño no sabe las condiciones de la emisión, de lo contrario no preguntaría. No vemos forma de salir de este círculo vicioso: para conocer el asentimiento tenemos que conocer las condiciones de emisión, y para conocer éstas necesitamos conocer el primero.

En suma, creemos que considerar el lenguaje como un conjunto de disposiciones no da una verdadera explicación, por su vaciedad, aunque pueda entenderse como una definición polémica. Nos adherimos, por lo demás, a la crítica de Chomsky de la probabilidad de una oración, y creemos que si esa probabilidad se hace relativa a las preguntas, entonces lo que tenemos es un lenguaje empobrecido de gritos e interjecciones. Por nuestra parte, creemos además que la restricción a los contextos interrogativos tampoco puede explicar, siquiera, las primeras expresiones lingüísticas presuntamente condicionadas, y esto porque los vocabularios infantiles previos a la adquisición de la habilidad de preguntar están muy nutridos de palabras de todas clases. ¿Cómo se explica entonces que esas palabras se aprendan como disposiciones si el niño carece del único método para identificar las disposiciones adultas que es la pregunta?

\section{La estructura holista del lenguaje}

Pero Quine concibe el lenguaje no sólo como un conjunto socialmente inculcado de disposiciones a la conducta verbal, sino también como un marco o

"W. V. Quine, Las raices de la referencia, p. 64. 
"red de oraciones asociadas entre sí y algunas de ellas con estímulos externos por el mecanismo de respuesta condicionada" 12 .

Y también:

El material lingüístico es un sistema interconectado, ligado aquí y allí con la experiencia. No es un conjunto de términos o enunciados establecidos independientemente unos de otros, cada uno con su particular definición empírica. No existe significado separado, en términos de experiencia directa, para el enunciado de que hay una mesa aquí... es el sistema como totalidad el que está conectado con la experiencia ${ }^{13}$.

Las oraciones, aisladamente consideradas, no tienen significado empírico separado, es el sistema como totalidad el que está conectado con la experiencia. Por supuesto, no hay otro tipo de significado que no sea empírico, rechazadas ya por Quine desde siempre las ideas o conceptos como entidades intermedias entre la palabra y el objeto. En el párrafo citado queda claro que Quine concibe el lenguaje natural como un sistema holista, al igual que las teorías científicas. Sin embargo, la anterior es una posición temprana, "ultraholista»; en ella no existen oraciones directamente conectadas con la experiencia, todas dependen unas de otras, es el sistema como totalidad el que está conectado con los estímulos.

Pero a partir de Palabra y objeto entran en acción sus famosas oraciones observacionales. Estas "encaran el tribunal de la experiencia aisladamente» ${ }^{14}$, no corporativamente. En ese sistema interconectado, o red, algunas oraciones privilegiadas, situadas en la periferia, tienen significado estimulativo propio, o sea, se puede decir que son emitidas en presencia de ciertos estímulos originalmente asociados con ellas mediante refuerzo. De esta forma, no son las palabras, sino las oraciones observacionales, las que están conectadas directa y originalmente con la experiencia. Las palabras y su conexión referencial con objetos son una adquisición, en cierto modo, "teórica» y más tardía. De las que no tienen el privilegio de poseer significado estimulativo por no estar en la periferia sino

12 W. V. Quine, «Reply to Chomsky», en D. DAvidson y J. HintikKa (eds.) op. cit., p. 310.

13 W. V. QuINE, "On mental entities", en QUINE, The ways of paradox and other essays, Cambridge, Mass., 1976, p. 222.

14 W. V. QUINe y J. S. Uluian, The web of belief, Nueva York, 1970, p. 13. 
en el interior de la red, lo más que podemos decir es que en vez de significado tienen "condiciones de verdad" derivadas de conexiones en el interior del sistema. La metáfora de la red contribuye a explicar este fenómeno: todo elemento de una estructura reticular se sostiene por sus conexiones con otros, y la estructura entera se sostiene por su anclaje, en este caso, en la experiencia.

\section{Métodos de aprendizaje del lenguaje}

Acabamos de ver la concepción conductista del lenguaje que tiene Quine. Convendrá ahora examinar los modos de aprendizaje de las primeras palabras. Para este menester tomaremos como fuentes principales el apartado «Modos de aprender palabras", correspondiente al capítulo I de Palabra y objeto, y el capítulo II del libro The web of belief escrito en colaboración con J. S. Ullian ${ }^{15}$. En esta última obra Quine distingue entre un método directo de adquisición del lenguaje, en el que las primeras expresiones se aprenden por confrontación directa con las situaciones del mundo y otros métodos indirectos en los que palabras y oraciones se aprenden a base de otras palabras y oraciones ya conocidas. El método directo recibe el nombre de aprendizaje ostensivo. Se trata del modo de aprender palabras que consiste en asociar éstas con estimulación presente mediante refuerzo. Es la forma más básica y primitiva de aprendizaje del lenguaje, aunque no la más potente. Quine reconoce que "sólo en parte aprendemos el lenguaje mediante asociación directa de términos u oraciones con observación; en otra parte lo aprendemos mediante la vinculación de términos y oraciones unos con otros» ${ }^{16}$.

Los otros métodos indirectos, ya lingüísticamente dependientes, son, según nuestro autor, la definición y la abstracción, si tratamos de aprender palabras y la sintesis analogica, si hablamos de formar oraciones.

Empecemos con el método definicional, aunque sea el de más tardío empleo. La definición más sencilla es la que podemos llamar directa. una palabra nueva es equiparada con otra u otras que ya conocemos. Desconocemos "soltero" y alguien nos la hace equivaler a "hombre no casado", suponiéndonos conocedores del uso de "hombre" $y$ "casado». De esta forma se aprenden al principio pocas palabras. Su importancia aumenta, sin embargo, durante la instrucción escolar.

15 W. V. Quine y J. S. Ullian, The web of belief, Nueva York, 1970.

16 W. V. QUINE, Las raices de la referencia, p. 54. 
El otro tipo de definición que se menciona en The web of belief es la contextual. En ésta la expresión desconocida no se iguala con otras palabras directamente sino que se dan instrucciones sistemáticas para traducir todas las oraciones que contengan la expresión desconocida a otras oraciones que no la contienen y que sí entendemos. De esta forma queda el término indirectamente definido, en realidad, eliminado. Supongamos que no sé qué significa la expresión «Si y sólo si» en la oración "P si y sólo si Q». Alguien me ofrece entonces la oración equiva-lente "Si $\mathrm{P}$ entonces $\mathrm{Q}$ y si $\mathrm{Q}$ entonces $\mathrm{P}$ ", que sí comprendo. Se me ha ofrecido una oración equivalente, pero no unos términos equivalentes. Siempre que aparezca el término desconocido puedo "parafrasearlon, ofrecer oraciones equivalentes a las que lo contienen, pero que ya no lo contienen. Quine pone también el ejemplo de parafrasear "Juan es hermano de Pedro": si alguien desconoce el significado de "hermano", se le ofrece "Juan es un varón distinto de Pedro cuyos padres son los padres de Pedro». Tal sería una definición contextual de «hermano».

Russell usó este método en su teoría de las descripciones definidas y Quine en su programa de eliminación de términos singulares. Bentham fue, según nuestro autor, el que descubrió la definición contextual, la cual supuso «una especie de revolución copernicana dentro de la semántica» ${ }^{17}$. En todo caso, ella tiene la gran utilidad de permitir deshacernos de implicaciones ontológicas no deseadas del uso de una palabra. Por ejemplo, si no queremos tener que cargar con que la palabra "Pegaso" tenga un significado en un cielo platónico para que la oración "Pegaso vuela» tenga sentido, entonces sustituimos el nombre por una descripción definida, pongamos «el caballo alado cazado por Belerofonte», y la oración queda parafraseada como «Existe algo que es un caballo y que fue cazado por Belerofonte y que vuela». Ha desaparecido "Pegaso" y el compromiso ontológico recae en el "algo" o en el "una cosa tal que», o sea, en lo que equivale a una variable de la lógica cuantificacional. Ser es ser el valor de una variable. Este es el famoso criterio quineano de compromiso ontológico. Además, la definición contextual nos hace ver que son las oraciones las verdaderas portadoras del significado, sea éste lo que sea, y no los términos. Estamos ante una tesis central de nuestro autor, la de la "prioridad semántica de las oraciones». Finalmente, para que las definiciones directa y contextual permitan ampliar el vocabulario del niño, éste debe poseer ya un acervo importante de palabras. Por eso Quine cree que las definiciones intervienen poco en los orígenes del desarrollo léxico.

17 W. V. Quine, Theories and things, Cambridge, Mass., 1981, p. 69. 
La fuente más importante de adquisición de palabras no es la ostensión, ni la definición, sino otro método llamado por Quine abstracción. Lo define como aquél por el que "captamos el uso de una palabra a partir de las oraciones en las que aparece" 18 . Las palabras se aprenden como fragmentos de oraciones aprendidas como totalidades. Las preposiciones, conjunciones y, en general, las palabras de relación tienen que aprenderse forzosamente de esta manera. Conseguimos usarlas por analogía con los modos en los cuales las hemos visto aparecer en oraciones anteriores. Pero también se aprenden por abstracción muchas palabras de contenido, sustantivos, adjetivos y verbos, aunque sean susceptibles también de aprendizaje ostensivo. Dice, además, que ese proceso de abstracción es «en gran medida inconsciente» ${ }^{19}$. No sabemos muy bien qué quiere decir Quine con eso. ¿Que es automático? ¿Que no tenemos control consciente de esa operación? ¿Que está oculto a nuestro análisis? Pero ¿cómo puede un conductista antimentalista admitir procesos inconscientes? Tampoco nos da muchos detalles sobre el método mismo, sólo alusiones vagas a "captar el uso" o "extraer el significado" que necesitan tanta explicación como la abstracción en cuestión.

La explicación básica del método no está clara. Vamos a tratar, sin embargo, de reelaborarla con un ejemplo que esté de acuerdo con su espíritu general. Quine dice que con este método aprendemos las palabras captando su uso en el interior de oraciones cuyas condiciones totales de verdad conocemos y no en presencia de sus objetos de referencia. Imaginemos cómo podría ocurrir este proceso. Por ejemplo, si el niño conoce las condiciones globales que permiten el asentimiento a la oración "El-gato-está-sobre-la-estera", considerada en bloque, entonces, y suponiendo que conoce otros bloques en los que aparece la parte "gato", termina por captar qué parte de la escena total resulta relevante para asentir sólo a "gato». Ha aprendido el uso del término "gato" desincrustándolo de unas condiciones globales de verdad. Aquí no hay más misterio, según Quine, que los procedimientos inductivos habituales: partes comunes ("gato") en varias oraciones que aparecen en éstas cuando en las situaciones globales correspondientes hay gatos, y partes diferentes ("estera") que aparecen con "gatos", cuando hay gatos, pero también cuando no los hay y sí están presentes las esteras.

El método de abstracción nos proporciona palabras, pero lo más importante son las oraciones. Quine afirma que una vez que disponemos de algunas palabras sueltas (sea por ostensión o por abstracción) podemos construir oracio-

18 W. V. QUINE, The web of belief, p. 14.

19 W. V. QUINE, op. cit., p. 14. 
nes utilizando esas pala- bras. Al método de construir oraciones que propone lo llama sustitución analogica. Por él formamos oraciones nuevas cuando en moldes viejos (oraciones conocidas como "Me duele el pie») introducimos una nueva palabra («mano») y obtenemos la nueva oración "Me duele la mano» ${ }^{20}$. Esto supone que previamente el niño debe conocer la vieja estructura de "Me duele el pie». Pero ¿cómo puede conocer una estructura si sólo ha tenido acceso a oraciones primitivas monolíticas ("Gato" o "El-gato-está-sobre-la-estera") y éstas no tienen estructura por definición? La alternativa es: si el niño conoce "me duele el pie» no puede ser más que como bloque, sin analizar en términos, o por construcción a base de palabras sueltas. Si es como bloque, no hay estructura que conocer: las oraciones primitivas son compactas, sin componentes. Si es por construcción, necesita conocer una estructura anterior en analogía con la cual, e incrustando una palabra nueva, pueda formar una nueva oración; pero entonces estamos en las mismas: ¿cómo puede conocer esa estructura anterior, como bloque o por construcción?

En general, pues, debemos tener una idea de lo que es la estructura de una oración, o sea, conocer sus partes, sus relaciones, las categorías que pueden sustituirse y las que no, debemos conocer la gramática de la lengua. Quine, sin pretenderlo, nos coloca ante el dilema de que para construir oraciones nuevas (eso es, en el fondo, la gramática) debemos conocer de antemano la gramática. Quizás sea esto lo que deba ocurrir, que necesitemos una gramática innata, como piensa Chomsky.

\section{La secuencia de las adquisiciones}

Hemos hablado de los métodos. Ahora nos toca reconstruir el orden general de las adquisiciones, palabras y oraciones, producidas por tales métodos. El niño empieza con oraciones observacionales de una sola palabra, holofrases como "Mamá», "Rojo», «Agua», dichas en las ocasiones en que su emisión es reforzada por los padres ante las situaciones estimulativas correspondientes. Se llaman "holofrases" porque son oraciones comprimidas en lo que parece una sola palabra. Esa palabra no se refiere a objetos, como ocurriria si fuera un término, sino a situaciones estimulativas globales. Ellas tienen un aprendizaje ostensivo puro: el niño comienza emitiendo holofrases ante escenas externas globales. Esta es nuestra entrada en el lenguaje. 
Pero con estas holofrases monolíticas poco se puede hacer. Las holofrases no son términos que puedan aprovecharse para definiciones o para componer oraciones nuevas. Quine, por lo tanto, necesita un segundo paso: suponer que el niño es capaz de aprender el significado (estimulativo) de oraciones de más de una palabra, pero en las que, paradójicamente, todavía no hay palabras; son oraciones que están constituidas, no por términos, sino por partes fonéticas que serán futuras palabras aunque de momento constituyan un solo bloque fonético y semántico. Las hemos visto en el apartado anterior y las vamos a llamar «holofrases complejas".

«El-gato-está-sobre-la-estera» puede aprenderse ostensivamente como una cadena unitaria de sílabas en asociación con cierto rango de escenas posibles ${ }^{21}$.

Cuando el niño llega a disponer de varios de estos bloques, se supone que podrá empezar a "abstraer" de ellos palabras sueltas con las que referirse ya a partes de la escena global. Estamos en el momento adecuado para iniciar el aprendizaje por abstracción. Las palabras así obtenidas, no tienen un puro aprendizaje ostensivo: dependen para su adquisición de que el niño disponga de holofrases simples y complejas. Su significado no es directamente estimulativo, conectado con el mundo externo, sino el resultado de un proceso (¿mental?) llamado "abstracción", que en el fondo vimos que se reduce a una inducción. Para aprender estas palabras no basta con mirar al mundo y dejarse reforzar. Hay que mirar a otras oraciones y averiguar inductivamente qué usos son admitidos y en qué circunstancias. En todo caso, el aprendizaje de palabras por abstracción guarda una conexión directa, si no con el mundo, sí con las oraciones observacionales ocasionales de las que son extraídas. Tanto «gato" como "estera" tienen una filiación directa con la experiencia, pues surgen del bloque conectado con ella que es «El-gato-está-sobre-la-estera».

El paso siguiente, la construcción de oraciones del tipo «me duele la mano" por sustitución analógica, también supone un alejamiento de la ostensión pura. Esas nuevas oraciones ya no son bloques conectados por condicionaminto con escenas globales sino oraciones léxicamente articuladas, compuestas por palabras con significados estimulativos relativamente independientes y que, sin embargo, no han perdido todavía su conexión con la experiencia porque hemos de suponer que están compuestas de palabras obtenidas en la fase anterior.

21 W. V. QuINE, The web of belief, p. 15. 
En suma, la secuencia de las primeras adquisiciones lingüísticas sería la siguiente: $\left.1 .^{\circ}\right)$ Holofrases simples aprendidas por condicionamiento directo, como «Rojo" en presencia de rojo. $2^{\circ}$ ) Holofrases complejas, bloques fonéticos inestructurados gramaticalmente, como «El-gato-está-sobre-la-estera», aprendidas como totalidades también por condicionamiento ante escenas externas correspondientes. $\left.3 .^{\circ}\right)$ Palabras aisladas, como "gato» o «estera", extraídas por abstracción de los bloques anteriores. Aquí nos alejamos un poco de la ostensión pues, más que del condicio- namiento, se necesita de una inducción de usos que implica un cierto cálculo mental entre las apariciones de las mismas palabras en distintas oraciones. $4^{\circ}$ ) Las palabras aisladas obtenidas por abstracción pueden utilizarse ahora para construir nuevas oraciones por síntesis o sustitución analógica. $\left.5^{\circ}\right)$ Por último, nuevas palabras se adquieren por definición.

El aprendizaje lingüísticamente dependiente. La asociación interverbal

Hemos visto que la abstracción y la definición son métodos indirectos, que dependen de lenguaje anterior. También la síntesis analógica exige dominar estructuras linguísticas anteriores. Quine 22 reconoce que si todo nuestro aprendizaje de oraciones se redujera a aprender éstas como totalidades por condicionamiento directo y a la producción de nuevas oraciones a partir de modelos conocidos por síntesis analógica, tendríamos poco más que un «mero registro de datos sensibles". Necesitamos no sólo la asociación de oraciones con estimulación no verbal, también la asociación de oraciones con otras oraciones y de palabras con otras palabras.

Se necesitan otras asociaciones interverbales que permitan el uso de oraciones nuevas sin vincularlas, ni siquiera derivativamente, con ámbitos fijos de estimulación no verbal ${ }^{23}$.

Lo que ocurre es que Quine no puede precisar cuál es el modo de asociación de esas oraciones interiores entre sí. Ciertamente queda claro que la red de oraciones (teoría o lenguaje) tiene en su periferia unas oraciones especiales asociadas con estímulos no verbales mediante respuesta condicionada. Respecto a las interiores, sin embargo, sólo dice que:

22 W. V. QUINE, Palabra y objeto, p. 23.

23 W. V. QuINE, op. cit., p. 24. 
(...) la red se compone de oraciones asociadas entre sí de varios modos que no son fáciles de reconstruir ni siquiera a título de conjetura simplificada. Andan en ello las conexiones lógicas y las llamadas "causales" 24.

Tratemos de precisar cuáles serían las conexiones lógicas. Por ejemplo, creemos que Quine está pensando en una relación como la implicación: una oración está asociada con sus consecuencias lógicas. Así "Sócrates es mortal», está asociada como una conclusión con «Sócrates es hombre» $\mathrm{y}$ "Todos los hombres son mortales".

¿Y las conexiones causales? Suponiendo nuestra teoría natural del mundo y que estoy ahora ante un bosque recién quemado, la oración "Aquí ha habido fuego", que no es observacional, pues en ese momento no se ve el fuego sino el resto humeante de un bosque, está asociada causalmente con la oración, esta sí observacional, "Aquí hay humo", pues estoy delante de él, ante estímulos humeantes. El fuego produce, causa, el humo. Quine llamará a oraciones del tipo "siempre que hay fuego, hay humo" categoricas observacionales 25 . En todo caso, las conexiones causales están reflejadas en las categóricas observacionales. Resumiendo lo anterior podemos decir que nuestro autor cree que toda teoría científica (como la química) o toda teoría natural (como nuestro lenguaje) es un edificio de oraciones diversamente conectadas entre sí (por vínculos lógicos y causales, y otros que no puede concretar) y con estímulos no verbales por el mecanismo de la respuesta condicionada. Ya hemos visto antes el carácter holista del lenguaje natural.

Pero lo que nos tiene que decir Quine es cuáles son esas otras asociaciones, además de las lógicas y las causales, que conectan unas oraciones con otras en el lenguaje natural. Está claro que las conexiones lógicas y causales caracterizan a las oraciones de una teoría científica que busca la verdad, y puede, incluso, que cuando el lenguaje natural se use sólo en forma enunciativa, valgan esas conexiones también. Pero nuestro lenguaje es mucho más amplio y complejo que una teoría. ¿Qué otro tipo de conexiones puede haber entre oraciones? No creemos que haya que buscar demasiado lejos si decidimos mirar sencillamente a lo que nos dice la gramática. Sabemos que las palabras guardan relaciones unas con otras de acuerdo con su papel distintivo o contrastante en la secuencia lineal de la oración, las llamadas por De Saussure relaciones sintagmáticas (sujeto,

24 W. V. QUINE, op. cit., p. 24.

25 Ver, por ejemplo, W. V. QuINE, Theories and things, p. 27. 
predicado...). También existen relaciones de las palabras con aquellas otras que pueden ejercer su misma función gramatical, relaciones paradigmáticas (nombre, verbo...). Además, sabemos que las oraciones se relacionan entre sí por un complejo (pero bien estudiado en la lingüística actual) sistema de transformaciones. De cualquier manera, las oraciones del lenguaje tienen unas interconexiones propias del sistema lingüístico, independientes de las de un sistema teórico. ¿Por qué, pues, declarar que no podemos precisar esas relaciones cuando la gramática las tiene perfectamente especificadas?

Si nuestro interés es el aprendizaje del lenguaje natural y no el apoyo evidencial de las teorías, de poco nos sirve modelar el lenguaje (cuyo objetivo es la comunicación "multipropósito" interpersonal) sobre la estructura de una teoría (cuyo único propósito es descubrir la verdad o seleccionar un conjunto de oraciones verdaderas).

\section{La posición de Chomsky}

A este respecto, es revelador el intercambio de ideas entre Quine y Chomsky. En su artículo ya citado, "Quine's empirical assumptions", Chomsky dice que "aprender un lenguaje no es aprender oraciones... más bien tenemos que desarrollar ciertos principios... que determinan la forma y significado de indefinidamente muchas oraciones. Una descripción del conocimiento del lenguaje... como una red asociativa construida por respuesta condicionada está en conflicto con cualquier evidencia que tengamos sobre estas materias (p. 71)" y «... debemos asumir que el conocimiento de una gramática universal, en el sentido más amplio, es una propiedad innata de la mente, y que este sistema dado de reglas y principios determina la forma y el significado de infinitamente muchas oraciones, a partir de la diminuta base empírica que nos es realmente disponible» (p. 59).

Ante esta declaración Quine contesta, en su también citada "Reply to Chomsky" ${ }^{26}$, diciendo que la respuesta condicionada sólo la considera presente en la periferia de la red, en las oraciones observacionales. Pero ¿cuáles son las otras formas de conexión no condicionadas que imperan dentro de la red? Chomsky contesta: la gramática universal. Quine dice que más allá de las oraciones observacionales todo está oscuro:

26 W. V. Quine, "Reply to Chomsky", en DAvidson, D., y HinttKKa, J. (eds.), op. cit., p. 310 . 
Tal es, después de todo, el aprendizaje semántico del lenguaje, una vez que uno va más allá de las oraciones observacionales: aprendemos las condiciones de verdad de algunas oraciones respecto a otras oraciones. Aprendemos así a usar las palabras componentes para formar nuevas oraciones cuyas respectivas condiciones de verdad son derivables. Cuáles de estas dependencias de valor de verdad son debidas al significado, o lenguaje, y cuáles pertenecen más bien a una teoría sustantiva ampliamente compartida, es, en mi opinión, una cuestión muy oscura. No es una mera vaguedad de terminología lo que hace indistinguibles a un lenguaje y a una teoría en este respecto 27.

Cree, pues, nuestro autor que, en el fondo, tanto en una teoría como en un lenguaje, el derivar las condiciones de verdad de unas oraciones de las condiciones de verdad de otras es una cuestión muy oscura: no sabemos qué oraciones están asociadas con qué otras por virtud puramente del significado lingüístico, o por compartir una información ampliamente distribuida por toda la red.

Así pues, más allá del aprendizaje ostensivo, Quine no es capaz de ofrecer una explicación de la red interverbal, que, por otra parte, considera indispensable para cualquier explicación del origen y estructura del lenguaje. Y no es capaz, creemos, no porque sea un asunto oscuro, sino porque con su teoría conductista del significado y del lenguaje no es posible tal explicación. Si no está dispuesto a admitir que las palabras tengan "intensión" o significado y que el niño deba tener representadas en su mente ciertas reglas gramaticales abstractas, entonces el lenguaje sólo le resultará concebible si es asimilable a un sistema extensional, como el que aparenta tener una teoría científica.

\section{Antimentalismo y Conductismo}

Hemos visto los problemas de considerar el habla humana como un conjunto de disposiciones en el más puro estilo conductista. Debemos ahora analizar el antimentalismo de Quine en su explicación del lenguaje. Quine ${ }^{28}$ cree que existen tres niveles de explicación en el asunto de la mente y el lenguaje: un nivel mentalista, otro conductista y otro fisiológico. El nivel fisiológico es el

27 W. V. QUINE, loc. cit., p. 310.

28 W. V. Quine, "Mind and verbal dispositions", en Gurtenplan, S. (ed.), Mind and language, Londres, 1975, p. 87. 
más profundo, aquél en el que se dan las verdaderas explicaciones causales. El nivel conductual es un nivel intermedio. En él estamos obligados a describir el lenguaje, en espera de que en el futuro se pueda alcanzar la explicación neurofisiológica. El mental es el más superficial y apenas merece el nombre de explicación. No obstante, cierto grado de explicación en términos mentalistas es inevitable. En Las ratces de la referencia distingue entre un mentalismo acritico y uno heurístico. El primero, que es rechazado enérgicamente, sostiene, según nuestro autor, que el lenguaje es un sistema de comunicación de ideas o significados. Sin embargo, las ideas, o conceptos, o significados, son entidades mentales innecesarias (porque todo lo que ellas presuntamente explican lo explican también las meras palabras) y confusas (porque no tienen un claro principio de identidad).

Cuando aprendemos un lenguaje aprendemos a asociar las palabras del mismo con las mismas ideas con que las asocian otros hablantes. Pero, ¿cómo sabemos que esas ideas son las mismas? Y por lo que hace a la comunicación, ¿qué nos importa eso? Todos hemos aprendido a aplicar la palabra "rojo" a la sangre, los tomates, las manzanas maduras y las langostas hervidas. Las ideas asociadas, la sensación asociada, será lo que sea. Pero el lenguaje se salta la idea y se asienta en el objeto. Pocas cosas son menos útiles que la idea para estudiar el lenguaje ${ }^{29}$.

Todo esto nos resulta familiar, forma parte de la crítica al significado que desde siempre ha hecho nuestro autor. No existen entidades mentales intermedias entre la palabra y el objeto ("el lenguaje se salta la idea y se asienta en el objeto"). Las palabras no están asociadas con significados (o ideas o conceptos mentales) sino con objetos o con otras palabras. La red del lenguaje es una asociación de palabras con palabras y de oraciones con oraciones y, en la periferia, unas pocas expresiones especiales (palabras y oraciones observacionales) asociadas con la experiencia (si adulta, una experiencia dividida en objetos, si infantil, una experiencia constituida por situaciones estimulativas globales). Lo pernicioso del mentalismo acrítico, piensa nuestro autor, es el recurso a las ideas o conceptos como entidades mentales intermedias entre la palabra y el objeto. La actitud de Quine de apartarse de las ideas y atender sólo a las palabras porque éstas están ahí fuera donde podemos verlas y oírlas, está naturalmente ligada a su perenne estrategia nominalista, además de a su conductismo. 
Pero, aunque rechace las ideas o conceptos, no cree que todas las entidades mentales hayan de dejarse de lado. Será necesario aceptar o postular algunas con la intención de sistematizar los fenómenos físicos, y sólo si se conciben como mecanismos físicos hipotéticos. Estamos ante el mentalismo heuristico. la admisión de entidades mentales como ayuda a la investigación, en tanto descubrimos los verdaderos mecanismos causales, que han de ser forzosamente de carácter físico. Concretamente Quine ${ }^{30}$ dirá que la semejanza perceptual, el principio del placer, las prominencias, las imágenes, son, en el fondo, entidades mentales, pues todas ellas consisten en procesos internos del sistema nervioso del organismo, no pertenecen a la conducta observable de éste. Ese mentalismo, siempre que se controle, tiene su utilidad como estimulante:

Las entidades mentales son inobjetables si se conciben como mecanismos físicos hipotéticos y se postulan exclusivamente con la intención de sistematizar los fenómenos físicos. Hay que postularlas con la esperanza de que ellas mismas se puedan someter un día a una explicación física completa ${ }^{31}$.

La cuestión es: ¿̇on suficientes las entidades mentales que él postula para explicar el aprendizaje del lenguaje?

Por su parte, el conductismo debe actuar, para Quine, como una especie de corsé que evite el exceso mentalista. Se trata de una etapa que hay que superar, pues al final serán las explicaciones en términos físicos las verdaderamente satisfactorias. Mientras tanto, hemos de contentarnos con el mínimo de supuestos mentalistas necesarios para la explicación de los fenómenos complejos del lenguaje.

En todo caso, creemos que en Las raices de la referencia mitiga Quine su conductismo. Ciertamente, nunca fue un "behaviorista" radical al estilo de Skinner, incluso a pesar de declarar en Palabra y objeto (p. 95) que el aprendizaje de las primeras palabras ocurre "en lo esencial» en la forma en que aparece en la obra de Skinner Verbal Behavior ${ }^{32}$. Pero en el conductismo radical de Skinner se niega la eficacia causal de las "variables intervinientes», o constructos hipotéticos, que pertenezcan al interior del organismo, aunque sean de carácter fisiológico. Que el análisis experimental de la conducta de una persona vaya directamente a las causas antecedentes del ambiente puede ser una restricción

\footnotetext{
30 W. V. QUINE, op. cit., p. 49.

31 W. V. QUNNE, op. cit. p. 49

32 B. F. SkINNER, Verbal Behavior, New Jersey, 1957.
} 
metódica con vistas a mantener la psicología dentro del ámbito científico, pero decir, como hace Skinner, que el comportamiento de una persona está determinado por sus contingencias ambientales, con exclusión de cualesquiera procesos internos, es ya una postura ontológica. Quine no sigue a Skinner tan lejos. El conductismo de Quine se hace, creemos, cada vez más "metodológico". Skinner prohibía "neurologizar», postular mecanismos neuronales explicativos. Quine, por su parte, sueña con que un día sus entidades mentales heurísticas y sus disposiciones conductuales sean transformadas en procesos físico-químicos del sistema nervioso; ahí estará la verdadera explicación causal, no en las contingencias del ambiente exclusivamente. En resumen, Quine es un mentalista heurístico, un conductista metodológico y un soñador fisicalista. 